\title{
PENGARUH KOMUNIKASI TERAUPETIK DENGAN INTENSITAS NYERI PERSALINAN KALA I FASE LATEN DI KLINIK DELIMA MEDAN TAHUN 2014
}

\author{
Dina Indarsita, Sri Utami, Rina Sari \\ Jurusan Keperawatan Poltekkes Kemenkes Medan
}

\begin{abstract}
Abstrak
Persalinan suatu proses membuka dan menipisnya serviks serta terjadinya kontraksi uterus sehingga menyebabkan nyeri pada proses persalinan. Nyeri pada persalinan merupakan suatu proses yang fisiologis tetapi menimbulkan ketakutan dan kecemasan yang dapat menganggu kelancaran proses persalinan. Manajemen nyeri pada persalinan dapat diterapkan secara nonfarmakologis, salah satunya adalah komunikasi terapeutik yang bertujuan untuk membantu mengurangi nyeri, kecemasan, dan waktu persalinan lebih pendek secara bermakna. Tujuan penelitian ini adalah untuk mengetahui pengaruh komunikasi terapeutik dengan intensitas nyeri persalinan kala I fase laten di klinik Delima Medan tahun 2014. Metodologi penelitian yang digunakan dalam penelitian ini adalah quasyeksperimen yang bersifat one group pretest-postest. Sampel yang diambil dalam penelitian ini adalah ibu inpartu kala I fase laten sebanyak 42 orang dengan menggunakan teknik pengambilan sampel secara accidental sampling. Analisis data menggunakan uji t-dependent. Dari Hasil penelitian diperoleh data bahwa mayoritas berusia 20-35 tahun sebanyak 33 responden $(78,6 \%)$, paritas primigravida sebanyak 15 responden $(35,7 \%)$, pendidikan SMA sebanyak 21 responden $(50,0 \%)$, dan pekerjaan IRT sebanyak 23 responden $(54,8 \%)$. Rata-rata intensitas nyeri sebelum dilakukan komunikasi terapeutik adalah 2,71 dengan standart deviasi 0,673, dan rata-rata intensitas nyeri sesudah dilakukan komunikasi 2,05 dengan standart deviasi 0,764. Hasil uji t-dependent menunjukkan ada pengaruh komunikasi teraupetik yang diberikan terhadap intensitas nyeri persalinan pada ibu inpartu kala I fase laten dengan nilai $p$ value $=0,000$. Penelitian ini membuktikan bahwa komunikasi terapeutik yang dilakukan dapat mengurangi intensitas nyeri persalinan pada ibu inpartu kala I fase laten. Oleh karena itu diharapkan agar bidan mampu menerapkan komunikasi terapeutik dengan baik dan benar sebagai salah satu intervensi untuk mengurangi intensitas nyeri dalam asuhan ibu bersalin normal.
\end{abstract}

Kata kunci: Komunikasi Terapeutik, Nyeri Persalinan, Kala I Fase Laten

\section{PENDAHULUAN}

\section{Latar Belakang}

Persalinan sering kali menjadi hal yang menakutkan bagi sebagian perempuan hamil. Kekhawatiran terhadap rasa nyeri yang akan mereka alami saat melahirkan dan bagaimana mereka akan bereaksi untuk mengatasi nyeri tersebut. Untuk itu menjadi kewajiban seorang bidan untuk membantu ibu mengatasi rasa tidak nyaman dalam persalinan (Farer, 1999, dalam Adriana, 2012, hal. 1).

Berdasarkan data dari Dinas Kesehatan Kota Medan diketahui jumlah ibu bersalin pada tahun 2011 sebanyak 51,015 orang $(95,23 \%)$, tahun 2012 sebanyak 44,757 orang $(84,18 \%)$ dan tahun 2013 sebanyak 33,354 orang $(62,1 \%)$.

Setiap tahun lebih dari 200 juta ibu bersalin, di mana didapatkan kelahiran berakhir dengan bayi hidup pada ibu yang sehat. Walaupun demikian pada beberapa kasus, kelahiran bukanlah peristiwa membahagiakan tetapi menjadi suatu masa penuh dengan rasa nyeri, rasa takut, penderitaan bahkan kematian (WHO, 2003, dalam Febrina, 2011, hal. 2).

Association for the study of pain mendefinisikan bahwa nyeri dalam persalinan merupakan pengalaman emosional dan sensori yang tidak menyenangkan yang muncul dari kerusakan jaringan secara aktual atau potensional yang menunjukkan adanya nyeri protektif bagi tubuh yang merupakan mekanisme protektif bagi tubuh dan menyebabkan individu bereaksi untuk menghilangkan rangsang nyeri tersebut (Judha, 2012, hal.73).

Nyeri adalah proses alamiah dalam persalinan. Apabila tidak diatasi dengan baik akan menimbulkan masalah lain. Rasa takut dan cemas yang dirasakan ibu dapat menganggu kelancaran proses persalinan. Manajemen nyeri persalinan dapat diterapkan secara farmakologis dan nonfarmakologis. Pendekatan secara non farmakologis tanpa penggunaan obat-obatan, sedangkan secara farmakologis melalui penggunaan obat-obatan. Manajemen nyeri non farmakologis lebih aman, sederhana dan tidak menimbulkan efek 
merugikan serta mengacu kepada asuhan sayang ibu, dibandingkan dengan metode farmakologi yang berpotensi mempunyai efek yang merugikan (Reeder, 2011, hal. 654).

Rasa nyeri persalinan dapat dikurangi, baik itu menggunakan metode farmakologi maupun non farmakologi yang terkait dengan tiga tujuan dasar pengurangan nyeri dalam persalinan yaitu mengurangi perasaan nyeri dan tegang, sementara pasien dalam keadaan terjaga seperti yang dikehendakinya menjaga agar pasien dan janinnya sedapat mungkin tetap terbebas dari efek depresif yang ditimbulkan oeh obat tanpa menganggu kontraksi otot rahim (Farer, 1996).

Penelitian yang dilakukan oleh Niven dan Gijsbers (1984) bertujuan untuk melihat perbandingan intensitas nyeri persalinan dengan nyeri lain diperoleh hasil bahwa nyeri persalinan melebihi sindrom nyeri lain yaitu, 88\% dari 73 penderita nyeri tungkai menerima intervensi farmakologis, $76 \%$ dari sampel $(\mathrm{n}=200)$ mengalami nyeri punggung selama kehamilan dengan insiden puncak pada usia kehamilan 24-28 minggu yang mengganggu aktivitas normal ibu, maka nyeri harus diberi intervensi metode pengendali nyeri demi kenyamanan dan keringanan si penderita (Mander, 2003, hal. 140).

Penelitian Indrawati (2011), di BPS Uut Maschon yang bertujuan untuk melihat metode nonfarmakologi yang digunakan bidan dalam mengurangi intensitas nyeri persalinan dan efeknya dengan 4 metode nonfarmakologi yang dilakukan pada 30 orang sampel diperolah hasil bahwa teknik pernapasan yaitu efek yang ditimbulkannya adalah nyeri ringan sebesar $20(66,7 \%)$ orang. Teknik pengaturan posisi yaitu efek yang ditimbulkan nyeri sedang sebesar 17 ( 56,7\%) orang, selanjutnya teknik message yaitu efek yang ditimbulkan nyeri ringan sebesar $25(83,3 \%)$ orang. Teknik konseling dengan efek yang ditimbulkan yaitu sebesar $17(56,7 \%)$ orang mengalami nyeri ringan.

Dalam menghadapi proses persalinan tidak semua pasien bisa dengan tenang menghadapinya, oleh karena itu bidan harus bisa tanggap dalam memberikan asuhannya, untuk itu komunikasi sangat dibutuhkan. Komunikasi dalam kebidanan diketahui mengandung nilai pengobatan atau teraupetik yang tujuannya dipusatkan untuk kesembuhan pasien, teknik komunikasi ini dikenal dengan komunikasi teraupetik.

Komunikasi Teraupetik didefinisikan sebagai komunikasi yang direncanakan secara sadar, dimana tujuan utamanya adalah untuk kesembuhan pasien. Komunikasi teraupetik memiliki peranan yang penting dalam membantu seorang klien dalam memecahkan masalah yang dihadapinya. Dengan memiliki keterampilan dalam berkomunikasi teraupetik, bidan diharapkan akan lebih mudah menjalin hubungan saling percaya dengan klien sehingga akan lebih efektif dalam mencapai tujuan asuhan kebidanan yang diterapkan (Taufik, 2010, hal. 25).

Komunikasi teraupetik dapat memberikan dampak teraupetik dengan mempercepat proses kesembuhan pasien. Langkah-langkah yang dapat dilakukan dalam komunikasi dengan ibu bersalin antara lain : menjalin hubungan yang mengenakkan dengan klien (rapport), hadir mendampingi klien selama persalinan, mendengarkan keluhan-keluhan pesien selama proses persalinan, memberikan sentuhan dalam pendampingan klien, memberikan informasi tentang kemajuan persalinan, memandu persalinan, mengadakan kontak fisik dengan pasien, memberi pujian kepada pasien atas usaha yang telah dilakukannya dan memberi ucapan selamat atas kelahiran bayinya (Wulandari, 2009, dalam Adriana, 2012, hal. 3).

Pentingnya komunikasi terapeutik dalam menurunkan rasa nyeri yang ditimbulkan oleh persalinan sangat diperlukan, oleh karena itu bidan dalam persalinan harus bisa membantu menimbulkan rasa percaya diri, karena bila klien gugup dalam persalinannya maka timbul rasa takut sehingga rasa nyeri akan semakin bertambah (Kartono, 1992).

Dari uraian di atas, maka peneliti tertarik untuk melakukan penelitian mengenai pengaruh komunikasi terapeutik dengan intensitas nyeri persalinan kala 1 fase laten di Klinik Delima Medan tahun 2014.

\section{Tujuan Penelitian}

1. Untuk mengetahui pengaruh komunikasi teraupetik dengan intensitas nyeri persalinan kala I fase laten di tahun 2014.

2. Untuk mengetahui intensitas nyeri sebelum dilakukan komunikasi teraupetik pada ibu inpartu kala I fase laten.

3. Untuk mengetahui intensitas nyeri sesudah dilakukan komunikasi teraupetik pada ibu inpartu kala I fase laten.

\section{Manfaat Penelitian}

1. Sebagai salah satu intervensi untuk mengurangi intensitas nyeri ibu selama proses persalinan.

2. Sebagai referensi dan memberikan informasi tambahan sehingga dapat meningkatkan pengetahuan tentang komunikasi terapeutik dan nyeri persalinan.

\section{METODOLOGI PENELITIAN}

\section{Desain Penelitian}

Desain penelitian yang digunakan dalam penelitian ini adalah metode quasy- eksperimen yang bersifat one group pretest-postest yaitu intervensi untuk mengidentifikasi pengaruh komunikasi terapeutik dengan nyeri persalinan kala I fase laten pada ibu inpartu sebelum dan sesudah dilakukan komunikasi terapeutik. berikut :

Bentuk desain ini dapat digambarkan sebagai

Skema 1 Desain Penelitian

\begin{tabular}{|l|l|l|}
\hline Pretest & Perlakuan & Postest \\
\hline 01 & $\mathrm{X}$ & 02 \\
\hline
\end{tabular}

Keterangan :

01 : Pretest dilakukan pada kelompok intervensi yang mengalami nyeri persalinan sebelum dilakukan komuniksai terapeutik 
02 : Postest dilakukan pada kelompok intervensi yang mengalami nyeri persalinan sesudah dilakukan komuniksai terapeutik

$\mathrm{X}$ : Intervensi (tindakan komunikasi terapeutik)

\section{Populasi dan Sampel}

Populasi

Populasi dalam penelitian ini adalah seluruh ibu inpartu kala I fase laten yang fisiologis yang mempunyai keluhan nyeri persalinan dengan partus pervaginam di klinik bersalin Delima Medan. Dari survei pendahuluan, data ibu yang melahirkan di klinik bersalin Delima Medan dari Februari sampai Mei tahun 2014 sebanyak 56 orang.ibu bersalin yang berada di klinik Delima Medan.

\section{Sampel}

Sampel adalah sebagian dari populasi yang dianggap mewakili seluruh populasi. Teknik pengambilan sampel yang digunakan dalam penelitian ini adalah secara accidental sampling yaitu sampel yang dipilih hanya berdasarkan ketersediaannya yaitu sampel yang berada di tempat yang tepat dan di waktu yang tepat sesuai dengan tujuan peneliti. Pengambilan sampel sesuai dengan criteria inklusi yang telah ditentukan oleh peneliti.

Kriteria inklusinya meliputi:

a. Ibu inpartu tanpa perlakuan induksi

b. Ibu inpartu dengan fase laten $(0-3 \mathrm{~cm})$

c. Ibu inpartu dengan dukungan suami

d. Ibu inpartu presentasi kepala dan tanpa penyulit

e. Ibu inpartu dan bersedia menjadi responden.

Menentukan sampel dengan menggunakan ketetapan absolut dan menggunakan rumus :

Keterangan :

$$
\mathrm{n}=\frac{\mathrm{N}}{1+\mathrm{N}(\mathrm{d})^{2}}
$$

$\mathrm{n}=$ Jumlah sampel

$\mathrm{N}=$ Jumlah populasi

$\mathrm{d}=$ Ketetapan relatif yang ditetapkan oleh peneliti $(0,05)$

Diketahui : $\mathrm{N}=56$

$$
\begin{gathered}
n=\frac{N}{1+N(d)^{2}} \\
n=\frac{56}{1+56(0,05)^{2}} \\
n=\frac{56}{1,14} \\
n=49
\end{gathered}
$$

dari rumus diatas maka di peroleh besar jumlah sampel dalam penelitiann ini adalah sebanyak 49 orang.

\section{Tempat dan waktu Penelitian}

Penelitian ini dilaksanakan di Klinik Delima Medan. mulai bulan Februari - Mei Tahun 2014

\section{Analisis Data}

Dalam melakukan analisis data, setelah semua data terkumpul, diolah dengan tujuan mengubah data menjadi informasi

Selanjutnya dilakukan analisis data. Analisis data pada penelitian ini menggunakan analisis univariat dan bivariat.

\section{Univariat}

Data yang bersifat kategorik dicari frekuensi dan persentasenya yakni data demografi ibu inpartu meliputi usia, status kehamilan (gravida), pendidikan, dan pekerjaan. Sedangkan data yang bersifat numerik dicari mean dan standart deviasinya yakni skala nyeri persalinan melalui statistik deskriptif. Hasil data dibuat dalam bentuk tabel.

\section{Bivariat}

Analisis bivariat digunakan untuk menguji pengaruh komunikasi terapeutik dengan nyeri persalinan kala I fase laten $(0-3 \mathrm{~cm})$. Dalam menganalisis data secara bivariat, pengujian data dilakukan dengan uji statistik uji t-dependen yaitu uji statistik Paired sample t-test untuk mengukur skala nyeri sebelum dan sesudah dilakukan komunikasi teraupetik pada kelompok intervensi dan diperoleh mean perbedaan sebelum dengan sesudah pada kelompok intervensi. Taraf signifikan $(\alpha=0.05)$, pedoman dalam menerima hipotesis : jika data probabilitas $(\mathrm{p})<0.05$ maka $\mathrm{H}_{0}$ ditolak dan apabila nilai (p) > 0,05 maka $\mathrm{H}_{0}$ gagal ditolak.

\section{Hasil Penelitian}

Penelitian ini dilaksanakan pada bulan FebruariMei 2014 di Klinik Delima Medan. Data diperoleh dengan mengkaji intensitas nyeri, dengan jumlah responden adalah sebanyak 42 orang.

Berdasarkan penelitian yang berjudul "Pengaruh Komunikasi Teraupetik Dengan Intensitas Nyeri Persalinan Kala I Fase Laten di Klinik Delima Medan Tahun 2014" disajikan dalam tabel distribusi frekuensi dan dijelaskan sesuai dengan tabel sebagai berikut :

\section{Analisis Univariat \\ a. Karakteristik Responden}

Tabel .1

\begin{tabular}{|c|c|c|}
\hline $\begin{array}{l}\text { Irakteristik } \\
\text { Persentase }(\%) \\
\end{array}$ & & Frekuensi \\
\hline $\begin{array}{ll}1 & \text { Umur }\end{array}$ & & \\
\hline$<20$ tahun & 2 & 4,8 \\
\hline 20-35 tahun & 33 & 78,6 \\
\hline$>35$ tahun & 7 & 16,7 \\
\hline Jumlah & 42 & 100 \\
\hline Gravida & & \\
\hline Primi gravida & 15 & 35,7 \\
\hline Secundi gravida & 10 & 23,8 \\
\hline Multi gravida & 14 & 33,3 \\
\hline Grande gravida & 3 & 7,1 \\
\hline Jumlah & 42 & 100 \\
\hline Pendidikan & & \\
\hline $\mathrm{SD}$ & 6 & 14,3 \\
\hline SMP & 13 & 31,0 \\
\hline SMA & 21 & 50,0 \\
\hline PT & 2 & 4,8 \\
\hline Jumlah & 42 & 100 \\
\hline Pekerjaan & & \\
\hline Bekerja & 19 & 54,8 \\
\hline Tidak bekerja & 23 & 45,2 \\
\hline Total & 42 & 100 \\
\hline
\end{tabular}

Distribusi Responden Berdasarkan Karakteristik Data Demografi Ibu Inpartu di Klinik Delima Medan Tahun 2014 
Berdasarkan tabel 1 dapat diketahui bahwa usia responden mayoritas berada pada rentang usia 20-35 tahun sebanyak 33 orang $(78,6 \%)$, status kehamilan responden mayoritas primi gravida sebanyak 15 orang $(35,7 \%)$, tingkat pendidikan responden mayoritas SMA sebanyak 21 orang $(50,0 \%)$, dan pekerjaan responden mayoritas tidak bekerja sebanyak 23 orang $(54,8 \%)$.

\section{b. Intensitas Nyeri Responden Sebelum diberikan Intervensi}

Tabel .2

Distribusi Responden Berdasarkan Intensitas Nyeri Sebelum diberikan Intervensi Kepada Ibu Inpartu kala I Fase Laten di Klinik Delima Tahun 2014

\begin{tabular}{ccc}
\hline \multicolumn{1}{c}{ Karakteristik } & Frekuensi & \% \\
\hline $\begin{array}{l}\text { Sebelum diberikan } \\
\text { komunikasi teraupetik }\end{array}$ & & \\
\hline Tidak ada nyeri & - & - \\
\hline Nyeri ringan & - & - \\
\hline Nyeri sedang & 17 & 40,5 \\
\hline Nyeri berat & 20 & 47,6 \\
\hline Nyeri sangat berat & 5 & 11,9 \\
\hline Jumlah & 42 & 100 \\
\hline
\end{tabular}

Berdasarkan tabel 5.2 dapat diketahui bahwa intensitas nyeri responden sebelum dilakukan komunikasi teraupetik mayoritas berada pada tingkatan nyeri berat sebanyak 20 orang $(47,6)$.

\section{c. Intensitas Nyeri Responden Sesudah diberikan Intervensi}

Tabel 3

Distribusi Responden Berdasarkan Intensitas Nyeri Sesudah diberikan Intervensi Kepada Ibu Inpartu Kala I Fase Laten di Klinik Delima Tahun 2014

\begin{tabular}{lcc}
\hline \multicolumn{1}{c}{ Karakteristik } & Frekuensi & \% \\
\hline $\begin{array}{l}\text { Sesudah diberikan } \\
\text { komunikasi teraupetik }\end{array}$ & & \\
\hline Tidak ada nyeri & - & - \\
\hline Nyeri ringan & 9 & 21,4 \\
\hline Nyeri sedang & 24 & 57,1 \\
\hline Nyeri berat & 7 & 16,7 \\
\hline Nyeri sangat berat & 2 & 4,8 \\
\hline Jumlah & 42 & 100 \\
\hline
\end{tabular}

Berdasarkan tabel 3 dapat diketahui bahwa intensitas nyeri responden sesudah dilakukan komunikasi teraupetik mayoritas berada pada tingkatan nyeri sedang sebanyak 24 orang $(57,1)$

\section{Analisis Bivariat}

Dalam menganalisis data secara bivariat, pengujian data dilakukan dengan uji statistik uji $t$ dependent paired t-test yaitu mengetahui adanya pengaruh komunikasi teraupetuk dengan intensitas nyeri persalinan ibu inpartu kala I fase laten. a. Pengaruh Komunikasi Teraupetik dengan Intensitas Nyeri

\section{Tabel.5}

Pengaruh Komunikasi Teraupetik dengan Intensitas Nyeri Ibu Inpartu Kala I Fase Laten di Klinik Delima Medan Tahun 2014

\begin{tabular}{|c|c|c|c|}
\hline Variabel & Mean & Pvalue & $\mathbf{N}$ \\
\hline $\begin{array}{lll}\text { Intensitas } & \text { nyeri sesudah }\end{array}$ & & & \\
\hline $\begin{array}{l}\text { dilakukan } \\
\text { teraupetik }\end{array}$ & 2,05 & 0,000 & 42 \\
\hline
\end{tabular}

Berdasarkan tabel 5.5 dapat diketahui bahwa dengan uji paired sample t-test diperoleh nilai $\mathrm{p}$ value 0,000 maka didapatkan $\mathrm{p}<\alpha(0,000<0,05)$ sehingga Ha dalam penelitian ini diterima yang berarti ada pengaruh komunikasi terapeutik terhadap intensitas nyeri persalinan kala I fase laten di klinik Delima Medan.

\section{Pembahasan}

\section{Intensitas Nyeri ibu inpartu sebelum diberikan} intervensi di Klinik Delima Medan

Berdasarkan tabel 2 intensitas nyeri ibu inpartu sebelum diberikan intervensi di Klinik Delima Medan adalah ada 20 responden $(47,6)$ yang mengatakan nyeri berada pada tingkatan nyeri berat.

Hal ini dikarenakan bahwa responden yang mengatakan nyeri berat memiliki rasa ketakutan dan kecemasan yang tinggi terhadap proses persalinan yang akan dilaluinya, serta kurangnya dukungan yang diberikan terhadap ibu.

Ibu yang akan bersalin biasanya mempunyai emosi berlebihan yang dapat menimbulkan suatu kecemasan. Kecemasan yang timbul dapat disebabkan karena dua faktor yaitu antara kesenangan dan rasa nyeri yang sedang dirasakan. Salah satu bentuk kecemasannya adalah berupa ansietas primer yang timbul karena tauma kelahiran (birth trauma), Salah satu bentuk kecemasan adalah freefloating anxiety yaitu suatu keadaan cemas dimana individu selalu memikirkan sesuatu hal yang buruk yang mungkin terjadi. Akibatnya ia akan selalu berada dalam keadaan cemas karena takut menghadapinya (Varney, 2001).

Nyeri persalinan menjadi lebih ringan seiring dengan makin sering dan efektifnya pengendalian nyeri. Bonica 1990 mengatakan bahwa menyiagakan wanita terhadap persalinan yang akan dihadapi akan dapat mengurangi nyeri. Ketegangan emosi akibat rasa cemas sampai rasa takut dapat memperberat presepsi nyeri selama persalinan. Nyeri atau kemungkinan nyeri dapat menginduksi ketakutan sehingga timbul kecemasan yang berakhir dengan kepanikan, keletihan dan kurang tidur yang dapat memperberat nyeri (metode dick-read).

Menurut teori bobak (2000) bahwa pengalaman melahirkan sebelumnya juga dapat mempengaruhi respon ibu terhadap nyeri. Bagi ibu yang belum mempunyai pengalaman melahirkan atau Ibu yang pertama melahirkan akan merasa cemas dan takut dalam menghadapi persalinan. Stres atau rasa takut secara fisiologis dapat 
menyebabkan kontraksi uterus menjadi terasa semakin nyeri dan sakit dirasakan.

Maryunani (2010) menjelaskan bahwa kecemasan yang dialami oleh ibu pada awal persalinan berhubungan dengan berbagai macam faktor yang terkait dengan proses persalinan. Dimana cara-cara untuk mengurangi kecemasan antara lain: memberikan informasi untuk mengetahui ketakutan yang jelas, membuat hubungan kerjasama dengan pendamping, menjadi pendengar yang baik, menunjukkan sikap simpatik, membantu dan komunikatif terhadap ibu yang akan bersalin.

Hal ini sesuai dengan penelitian yang dilakukan oleh Indrawati (2011) di BPS Uut Maschon, juga melakukan penelitian yang serupa tentang metode konseling dalam pengurangan rasa nyeri persalinan dan didapatkan hasil dari $30(100 \%)$ responden, ada sebanyak $17(56,7)$ responden mengalami nyeri ringan.

\section{Intensitas Nyeri ibu inpartu sesudah diberikan intervensi di Klinik Delima Medan}

Berdasarkan table 3 intensitas nyeri ibu inpartu sesudah diberikan intervensi di Klinik Delima Medan adalah ada 24 responden $(57,1)$ yang mengatakan nyeri berada pada tingkatan nyeri sedang.

Hal ini dikarenakan bahwa responden yang mengatakan nyeri sedang sudah lebih siap secara psikologis dalam menghadapi proses persalinan sehingga ibu lebih percaya diri dan tidak takut dalam menghadapi proses persalinannya.

Sesuai yang dikemukan Fraklin (2000), bahwa jika ibu diperhatikan dan diberi dukungan selama persalinan dan kelahiran bayi serta mengetahui dengan baik mengenai proses persalinan dan asuhan yang akan mereka terima, maka akan mendapatkan rasa aman dan keluaran yang baik.

Langkah-langkah yang dapat dilakukan dalam melakukan komunikasi antara lain: menjalin hubungan yang mengenakkan dengan klien, hadir mendampingi klien, mendengarkan keluhan-keluhan klien, memberikan sentuhan dalam pendampingan klien, memberikan informasi kepada klien, mengadakan kontak fisik dengan klien, memberi pujian kepada klien atas usaha yang telah dilakukannya.

Pentingnya komunikasi terapeutik dalam menurunkan rasa nyeri yang ditimbulkan oleh persalinan sangat diperlukan, oleh karena itu bidan dalam persalinan harus bisa membantu menimbulkan rasa percaya diri, karena bila klien itu sendiri merasa gugup dalam menghadapi persalinannya baik fisik ataupun mental belum siap maka timbul rasa ketakutan sehingga rasa nyeri akan semakin bertambah (Kartono, 1992).

Hal ini sesuai dengan penelitian sebelumnya yang dilakukan oleh Adriana (2012) terkait dengan pengaruh komunikasi teraupetik bidan terhadap intensitas nyeri persalinan, didapatkan hasil bahwa setelah diberikan komunikasi teraupetik terjadi perubahan atau penurunan tingkat nyeri yang sangat berarti dimana $p$ value $=0,000$ yang berarti $(\mathrm{P}<0,05)$. Hasil ini menunjukkan bahwa komunikasi terapeutik mempunyai pengaruh yang signifikan dalam menurunkan nyeri persalinan.

\section{Pengaruh Komunikasi Teraupetik dengan Intensitas Nyeri Pesalinan Kala I Fase Laten di klinik Delima Medan}

Pada penelitian ini berdasarkan uji statistik $t$ dependent pada tingkat signifikan $\alpha=0,05$ (95\%), ), maka didapatkan $\mathrm{p}<\alpha(0,000<0,05)$. Berarti Ho ditolak, maka secara statistik menunjukkan adanya pengaruh yang signifikan antara komunikasi teraupetik dengan pengurangan intensitas nyeri persalinan pada ibu inpartu kala I fase laten di klinik Delima Medan.

Hal ini sesuai dengan penelitian sebelumnya yang dilakukan oleh Yusnita (2012), juga melakukan penelitian yang serupa tentang komunikasi teraupetik dan diperoleh hasil ada pengaruh komunikasi teraupetik terhadap nyeri persalinan pada ibu inpartu diruang kebidanan dan bersalin Rumah Sakit Umum Daerah Kabupaten Pidie berdasarkan hasil uji statistik didapatkan nilai $\mathrm{p}<0,05$ (0.004) sehingga hipotesa alternatif dalam penelitian ini diterima.

Pengaruh yang signifikan ini dipengaruhi banyak hal antara lain bersangkutan dengan Sikap, perilaku dan komunikasi bidan dalam berinteraksi dianggap berpengaruh terhadap kondisi yang dialami ibu. Penjelasan dari bidan dalam berinteraksi akan menurunkan ketakutan dan stres psikis ibu.

Komunikasi merupakan salah satu bentuk kewajiban penolong terhadap hak pasien untuk memperoleh informasi objektif dan lengkap tentang apa yang dialaminya. Komunikasi yang baik akan sangat membantu terbinanya hubungan antar manusia yang serasi diantara pasien dan penolong, keserasian hubungan sangat diperlukan dalam memperoleh rasa saling percaya (Safuddin, 2004 dalam yusnita, 2012.Hal.1).

Menurut Suryani (2008) komunikasi terapeutik pada ibu melahirkan merupakan pemberian bantuan pada ibu yang akan melahirkan dengan kegiatan bimbingan proses persalinan. Komunikasi dilaksanakan oleh bidan dengan memberikan penguatan kepada ibu bersalin.

Menurut beberapa teori yang ada bahwa nyeri persalinan yang timbul karena adanya rasa kecemasan, ketakutan dan kepanikan, yang dapat memperberat nyeri persalinan akan mampu diatasi dengan pemberian komunikasi terapeutik, dimana terlihat bahwa tujuan dari komunikasi terapeutik itu sendiri adalah mengurangi beban pikiran rasa takut dan cemas yang dihadapi oleh pasien, mengurangi keraguan yang ada pada diri sendiri dan mempengaruhi orang lain, lingkungan fisik dan dirinya sendiri (Damaiyanti, 2008).

\section{Keterbatasan Penelitian}

Keterbatasan penelitian disini adalah pada pengukuran intensitas nyeri tidak sama pada setiap responden, ini disebabkan kedatangan pasien yang berbeda, dimana pasien datang pembukaannya tidak semua sama antara responden yang satu dan responden yang lainnya. Dan keterbatasan lainnya adalah pada responden yang primigravida sering terjadi perlakuan komunikasi 
yang terputus-putus. Hal ini dikarenakan pada primigravida banyak responden yang minta untuk pulang kerumahnya dulu dan akan kembali keklinik jika nyeri yang ia rasakan sudah sangat tak terhanakan lagi

\section{Kesimpulan}

1. Ada pengaruh yang signifikan terhadap intensitas nyeri sesudah dilakukan komunikasi teraupetik dengan $\alpha=0,05(95 \%)$ Nilai $\mathrm{p}(0,000)$, maka didapatkan $\mathrm{p}<\alpha(0,000<0,05)$

2. Ada 20 responden $(47,6)$ yang mengatakan mengalami nyeri berat sebelum dilakukan intervensi komunikasi teraupetik

3. Ada 24 responden $(57,1)$ yang mengatakan mengalami nyeri sedang sesudah dilakukan intervensi komunikasi teraupetik

\section{Saran}

Berdasarkan hasil penelitian dan kesimpulan diatas maka peneliti memberikan sedikit saran berdasarkan pemikiran serta pengetahuan sederhana sebagai berikut :

1. Diharapkan agar petugas kesehatan di klinik maupun rumah sakit bersalin untuk dapat meningkatkan pelayanan kesehatan pada ibu bersalin dengan penerapan metode komunikasi terapeutik yang baik sebagai salah satu intervensi dalam mengurangi nyeri persalinan

2. Diharapkan agar institusi pendidikan untuk lebih meningkatkan perkembangan ilmu kebidanan sehingga dapat meningkatakn pengetahuan peserta didik terutama mengenai asuhan pada ibu dalam masa persalinan

3. Diharapkan agar peneliti selanjutnya untuk dapat lebih memperluas penelitian ini guna mendapatkan hasil yang dapat memberikan pembaharuan dalam upaya peningkatan kesehatan ibu dalam masa persalinan.

\section{DAFTAR PUSTAKA}

Ancheta. R, \& Simkin. P. (2005). Buku Saku Persalinan. Jakarta : EGC

Bangun, Adriana. (2012). Pengaruh Komunikasi Teraupetik Terhadapa Intensitas Nyeri Persalinan Kala I Fase aktif di Klinik Santi Medan. Skripsi Fakultas Keperawatan Universitas Sumatera Utara. Diambil pada tanggal $\quad 18 \quad$ November 2013 http://www.repository.usu.ac.id

Bare, B. G., dan Smeltzer, S. C. (2001). Buku Ajar Keperawatan Medikal Bedah Brunner dan Suddarth. Jakarta : EGC
Bari Saifudin, A (2002). Buku Acuan Nasional Pelayanan Kesehatan Maternal Dan Neonatal. Jakarta : Yayasan Bina Pustaka. Sarwono Prawirohardjo

Bobak, I. M., at all. (2004). Keperawatan Maternitas. Jakarta : EGC

Farrer, Hellen. (2001). Perawatan Maternitas (Terjemahan). Jakarta : Penerbit Buku Kedokteran EGC

Indrawati. (2011). Metode Konseling Dalam Pengurangan Rasa Nyeri Persalinan di BPS Uut Maschon. Diambil pada tanggal 18 November 2013 dari http://www.dinamikakebidanan.com

Indrawati. T, Sujianto. U, \& Uripni. C. L. (2002). Komunikasi Kebidanan. Jakarta : Penerbit Buku Kedokteran EGC

Jones - Lewellyn, D. (2002). Dasar-Dasar Obstetri Dan Ginekologi Edisi 6 (Terjemahan). Jakarta : Hiprokates.

Leveno, K., J. (2009). Obstetri Williams. Ed-21. Jakarta : EGC

Mander, R. (2003). Nyeri Persalinan. Jakarta : EGC

Meiliasari, M., dan Danuatmaja, B. (2004). Persalinan Normal Tanpa Rasa Sakit. Jakarta : Puspa Swara

Notoatmodjo, S. (2005). Metodologi Penelitian Kesehatan. Jakarta : Rineka Cipta

Nursalam. (2008). Konsep dan Penerapan Metodologi Penelitian Ilmu Keperawatan. Jakarta : SalembaMedika

Prawirohardjo, S. (2005). Ilmu Kebidanan. Yogyakarta : Yayasan Bina Pustaka Sarwono Prawirihardjo

Purwanto, H (1994). Komunikasi Untuk Perawat. Jakarta : Penerbit Buku Kedokteran EGC.

Sugiyono. (2006). Metode Penelitian Administrasi. Jakarta : Cv Alfabeta

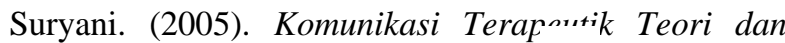
Praktek. Jakarta : Penerbit I । Kedokteran EGC

Varney, H. (2002). Buku Saku Bidan. Jakarta : Penerbit Buku Kedokteran EGC

Walsh, L. V. (2007). Buku Ajar Kebidanan Komunitas. Jakarta : EGC

Yusnita, R. (2012). Pengaruh komunikasi teurapetik bidan terhadap nyeri persalinan pada ibu bersalin di ruang kebidanan dan bersalin Rumah Sakit Umum Daerah Kabupaten Pidie. Diambil pada tanggal 18 November 2013 dari http://www. Journal.cpp//indexd/html

Yuswanto. T. J. A, dan Yulifah. R. (2009) Komunikasi dan Konseling dalam Kebidanan. Jakarta : Penerbit Salemba Medik. 